\title{
Studi Kabel Penghantar pada Instalasi Listrik Gedung Pertemuan Unhas Berstandarisai PUIL 2011
}

\author{
Muhammad Imran Bachtiar ${ }^{1)}$, Kazman Riyadi ${ }^{2)}$ \\ ${ }^{1}$ Teknik Elektro, Polteknik Negeri Ujung Pandang, ${ }^{2}$ Teknik Elektro, Polteknik Negeri Ujung Pandang \\ email:muh.imranb@poliupg.ac.id ${ }^{1}$, :kazmanriyadi@poliupg.ac.id ${ }^{2}$
}

\begin{abstract}
Gedung pertemuan yang digunakan secara umum memiliki fungsi sebagai sarana penunjang acara dan kegiatan. Adanya resiko kebakaran yang dapat terjadi pada suatu gedung baik secara langsung maupun tidak langsung menjadi perhatian tersendiri dalam menjaga keamanan suatu Gedung. Ancaman kebakaran dapat mengurangi rasa aman, sehingga perlunya penanggulangan dan pengendalian terhadap kebakaran tersebut, tindakan preventif pemeriksaaan kelayakan sebuah instalasi pada suatu bangunan sebagai implementasi peraturan perundang-undangan ketenagalistrikan perlu diterapkan dalam mencegah kebakaran. Studi penelitian dilakukan pada instalasi instalasi listrik Gedung bertingkat dengan menekankan fungsi kabel sebagai penghatar listrik berkesesuaian dengan PUIL (Persyaratan Umum Instalasi Listrik) 2011 yang berlaku dengan tujuan untuk meningkatkan keamanan terhadap resiko kebakaran akibat kabel Penghantar pada instalasi listrik Gedung bertingkat. Hasil yang diperoleh bahwa luas penampang kabel penghantar jenis NYY 3x2,5 mm², 4x10mm2, masing diproteksi dengan MCB 10A dan 32A sedangakan NYY 4xl6mm² diproteksi oleh MCB 60A sesuai dengan persyaratan PUIL 2011 yang berlaku. Berdasarkan hasil tersebut dapat meningkatkan keamanan terhadap resiko kebakaran akibat penghantar listrik (kabel) pada instalasi listrik di Gedung bertingkat.
\end{abstract}

Keywords: Persyaratan Instalasi, listrik, Kebakaran,

\section{PENDAHULUAN}

Sebuah gedung pertemuan digunakan secara komersial dan umum, sebagai sarana penunjang kegiatan acara-acara resepsi pernikahan dan sejenisnya yang dikelolah oleh Universitas Hasanuddin. Gedung ini dibangun di atas luas lahan $5000 \mathrm{~m} 2$ dengan konstruksi bangunan terdiri dari 2 lantai. Fungsi utama sebuah gedung umumnya dilakukan di lantai 1 . Adapun luas bangunan sekitar $1200 \mathrm{~m} 2$. Gedung ini dilengkapi dengan sistem listrik penerangan dan daya serta sistem tata udara yang mana daya listrik dipasok langsung oleh PLN agar dapat beroperasi sebagaimana fungsinya.

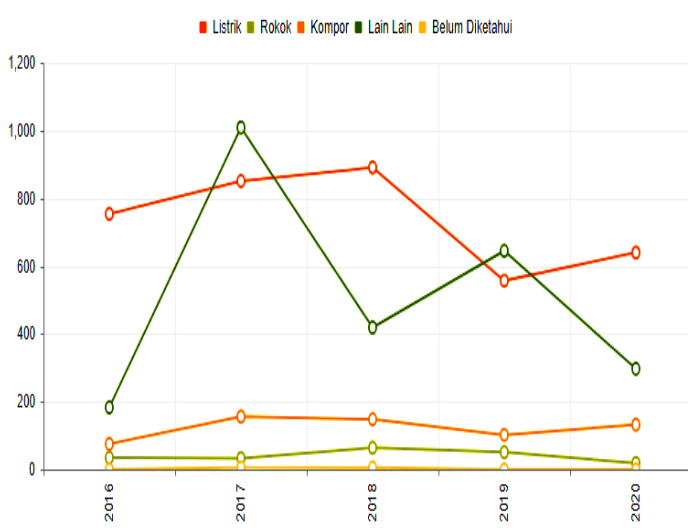

Gambar 1. Grafik kebakaran berdasarkan penyebabnya pada suatu Kota
Harapan akan keamanan dan kenyamanan dalam pengoperasian gedung merupakan dambaan setiap insan. Adanya resiko kebakaran yang dapat terjadi pada suatu bangunan baik secara langsung maupun tidak langsung menjadi perhatian tersendiri dalam menjaga keamanan suatu gedung. Data penanggulangan kebakaran memperlihatkan dalam bentuk grafik bahwa kebakaran yang terjadi akibat hubung-singkat listrik (korsleting listrik) adalah teratas setelah penyebab dari rokok dan kompor, gambar 1.1 memperlihatkan data grafik jumlah kasus kebakaran disuatu daerah yang terjadi peningkatan hingga 640 kasus ditahun 2020, walaupun di tahun-tahun sebelumnya pernah mengalami penurunan kasus kebakaran akibat listrik [1]. Bencana kebakaran tentunya mengakibatkan kerugian hilangnya harta benda bahkan jiwa [3]. Hal tersebut mendorong untuk diperlukannya studi tentang instalasi listrik pada sebuah gedung.

Ancaman kebakaran dapat mengurangi rasa aman, sehingga perlunya penanggulangan dan pengendalian terhadap kebakaran tersebut [4], tindakan preventif juga diperlukan dalam mencegah kebakaran seperti dengan melakukan deteksi dini terjadinya kebakaran [5],[6] ataupun dapat dilakukan dengan melakukan pemeriksaaan kelayakan sebuah instalasi 
berumur pada suatu bangunan [1]. Edukasi resiko kebakaran perlu disosialisasikan dan faktor aman melalui regulasi persyaratan kelistrikan juga dianggap penting dalam mencegah kebakaran.[7]

Studi penelitian dilakukan pada instalasi instalasi listrik fungsi kabel sebagai penghatar listrik berkesesuaian dengan PUIL (Persyaratan Umum Instalasi Listrik) yang berlaku. Selain itu dalam pemilihan kabel juga ditentukan pula sistem pengaman kabel agar sifat dan fungsi sebagai penghantar arus listrik tetap andal dan aman. Tujuan penelitian ini untuk meningkatkan keamanan terhadap resiko kebakaran akibat kabel penghantar pada instalasi listrik gedung bertingkat

\section{LISTRIK \& BAHAYA KEBAKARAN}

Terjadinya kebakaran karena adanya tiga unsur api yaitu Bahan bakar (Fuel), Sumber panas (Heat), dan Oksigen, terkandung dalam udara. Unsur-unsur api tersebut dikenal dengan segitiga api (fire triangle). Untuk unsur bahan bakar dapat berupa bahan bakar padat, cair dan gas yang dapat terbakar yang bercampur dengan oksigen dari udara [6]. Sumber panas menjadi salah satu penyebab kebakaran yang dapat bermula dari adanya korsleting listrik (Hubung-Singkat) yang menyebabkan meningkatnya arus listrik pada penghantar dalam waktu sangat singkat yang dapat menimbulkan panas lebih yang tinggi hingga membuat kabel terbakar dan membakar lingkungan sekitarnya. Hal ini secara bertahap mulai dari tahap penyalaan, hingga tahap pertumbuhan api dan pembakaran penuh yang menghasilkan gas dan asap dari bahan yang terbakar, dan dapat mencapai tahap maksimal yang menghanguskan serta membahayakan keselamatan jiwa akibat temperature/suhu yang sangat tinggi ataupun gas asap yang dihasilkan dari proses pembakaran tersebut. Hingga mencapai tahap akhir surut jika material yang terbakar telah habis dan temperature ruangan berangsur turun [8].

Bencana kebakaran yang disebabkankan oleh korsleting listrik dapat disebabkan oleh beberapa faktor seperti Penyambungan rangkaian instalasi listrik yang tidak memenuhi standar aturan seperti ditemuinya kabel yang sudah usang/tidak layak dan terkelupas, Kotak kontak umumnya dipasang 2-3 titik stop kontak penyambung, sehingga rentan terjadinya konsleting karena beban berlebih atau sambungan kontak yang tidak terpasang baik, hingga material yang tidak berstandar SNI [7], ataupun tidak dilakukannya pemeriksaan instalasi listrik berkala pada instalasi terpasang [1].

Salah satu persyaratan dalam instalasi listrik adalah dengan berpedoman pada PUIL 2011 yang bertujuan terhindarnya dari bahaya kebakaran dengan penentuan arus lebih dan arus hubung singkat sehingga kemampuan hantar arus listrik pada kabel penghantarnya sesuai dengan yang ditentukan kapasitas Hantar arus (KHA) tabel 1.1 memperlihatkan kapasitas hantar arus kabel tembaga dengan pemasangan luar yang mewakili luas penampang kabel dengan nilai $2,5 \mathrm{~mm}^{2}$ hingga $95 \mathrm{~mm}^{2}$ [9][10].

Tabel 1.1 Kapasitas Hantar Arus pada kabel tembaga dengan pemasangan luar

\begin{tabular}{ccc}
\hline $\begin{array}{c}\text { Luas } \\
\text { Penampang } \\
\text { Nominal } \\
\text { Konduktor } \\
\left(\mathrm{mm}^{2}\right)\end{array}$ & $\begin{array}{c}\text { Arus } \\
\text { Maksimum } \\
\text { yang } \\
\text { diperbolehkan } \\
(\mathrm{A})\end{array}$ & $\begin{array}{c}\text { Arus } \\
\text { Pengenal } \\
\text { Pengaman } \\
\text { MCB } \\
(\mathrm{A})\end{array}$ \\
\hline 4 & 25 & 20 \\
\hline 6 & 34 & 32 \\
\hline 10 & 43 & 40 \\
\hline 16 & 60 & 50 \\
\hline 25 & 80 & 63 \\
\hline 35 & 101 & 85 \\
\hline 50 & 125 & 100 \\
\hline 70 & 153 & 125 \\
\hline 95 & 196 & 170 \\
\hline
\end{tabular}

Semakin besar diameter kabel maka semakin tinggi kemampuan hantar arus yang dimiliki oleh penghantar kabel tersebut, selain itu jenis kabel juga mempengaruhi isolator yang menyelubungi penghantar juga mempengaruhi keamanan kabel sebagai penghantar arus listrik juga akan berbeda jenis kabel dan kemampuan pada jenis tegangan yang berbeda [11], [12]. Dalam pemilihan kabel sebagai penghantar maka ada beberapa parameter yang diperlu diperhatikan, diantaranya arus beban, daya maksimal beban, kondisi penggunaan beban, metode pemasangan kabel, Kapasitas penghatar listrik dapat ditentukan dengan jenis dan diameter (luas penampang) dari kabel itu sendiri dengan Tabel 1.1 KHA pada kabel Penghantar penentuan Kemampuan Hantar Arus (KHA) 
dari, terdapat beberapa jenis penghantar [10]. Untuk penentuan nilai arus dapat menggunakan persamaan berikut [13],[14],[15].;

$$
\begin{aligned}
& V=I x R \\
& P=V x I x \operatorname{Cos} \emptyset \text { atau } \\
& i=\frac{P}{V x \cos \emptyset}
\end{aligned}
$$

Sedangkan perhitungan pada daya tiga phasa, adanya penambahan faktor $\sqrt{3}$ akibat perbedaan tiap sudut phasa.

$$
\begin{gathered}
i=\frac{S}{\sqrt{3} \times V} \\
\text { Dimana } \\
\quad ;=\text { ArusListrik }(A) \\
V=\text { Tegangan Listrik }(V) \\
P=\operatorname{DayaListrik}(W)
\end{gathered}
$$

\section{METODE PENELITIAN}

Dalam penelitian ini dilakukan dengan melakukan pemeriksaan luas penampang kabel penghantar pada suatu instalasi Gedung bertingkat yang akan dibandingkan kesesuaian dengan Persyaratan Umum Instalasi Listrik (PUIL) 2011 untuk memperoleh hasil kelayakan operasi pada Instalasi Listrik tersebut. Penelitian dilakukan melalui observasi gambar rangkaian panel single line diagram dari beberapa perlengkapan Hubung Bagi (PHB) panel listrik dan proteksi arus pengenal untuk Gawai Proteksi Arus Lebih (GPAL) terhadap kabel penghantar yang digunakan bersesuaian dengan regulasi PUIL yang berlaku. Gambar 1.2 dan 1.3 merupakan denah bangunan yang akan diamati.

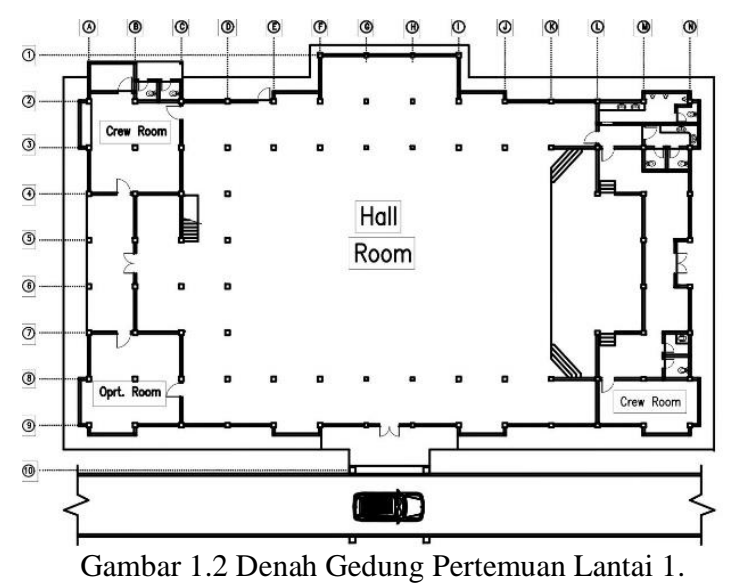

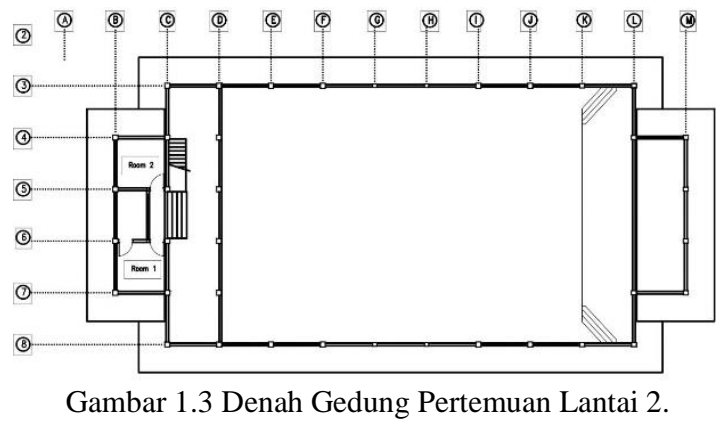

\section{HASIL DAN PEMBAHASAN}

Berdasarkan denah bangunan pada gambar 1.2 dan gambar 1.3 maka diperoleh Single Line Diagram instalasi listrik yang dapat dilihat pada gambar 1.4 dan gambar 1.5. Single Line Diagram tersebut memperlihatkan sebuah PHB (Perlengkapan Hubung Bagi) dari sebuah sistem penerangan dan daya dengan Gawai Proteksi Arus Lebih (GPAL). Pengamatan mengacu pada gambar 1.4 PHB melayani beban listrik dalam 11 group yang masing-masing mulai dari daya 800 watt hingga 1.280 watt dengan luas penampang kabel penghantar $2,5 \mathrm{~mm}^{2}$ dengan Gawai Proteksi Arus Lebih (GPAL) menggunakan MCB 10 Ampere di masing-masing groupnya, sedangkan $\mathrm{MCB}$ utama menggunakan 43 Ampere dengan luas penampang kabel utama PHB NYY 4x10 $\mathrm{mm}^{2}$.

Gambar 1.5 PHB melayani beban listrik dalam 6 group yang melayani beban 5.500 Watt 3 phasa dengan luas penampang kabel penghantar $2,5 \mathrm{~mm}^{2}$ dengan Gawai Proteksi Arus Lebih (GPAL) menggunakan MCB 16 Ampere di masing-masing groupnya, sedangkan MCB utama menggunakan 63 Ampere dengan luas penampang kabel utama PHB NYY 4x16 $\mathrm{mm}^{2}$.

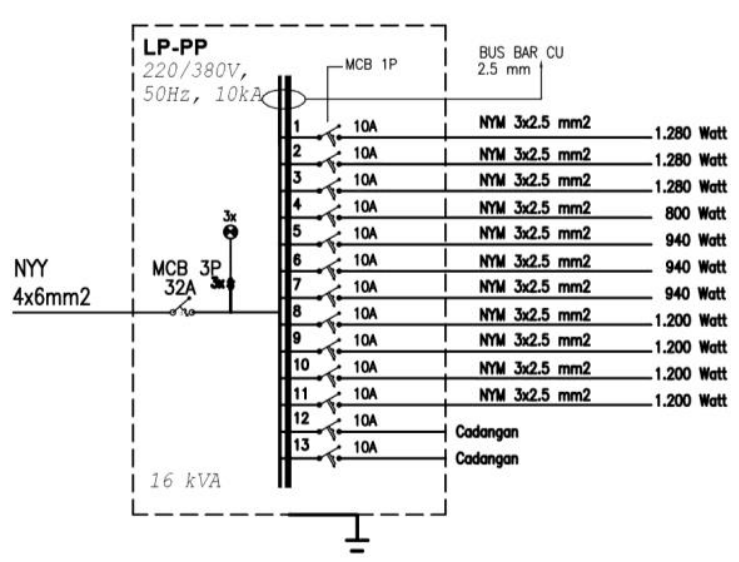

Gambar 1.4 Sistem Perlengkapan Hubung Bagi peruntukan Penerangan dan Kotak Kontak. 
Hasil pengamatan berdasarkan realita pemasangan instalasi listrik dan diagram single line dapat diukur arus nominal dari tiap group menggunakan persamaan (2) hasil perhitungan arus nominal tiap group dapat dilihat pada tabel 1.2 yang diperoleh arus tertinggi 6,85 A dengan luas penampang $2,5 \mathrm{~mm}^{2}$ dengan pengaman arus 10 A masih sesuai dengan PUIL 2011.

$$
\begin{aligned}
i_{\text {Nom }} & =\frac{P}{V x \cos \varnothing} \\
& =\frac{1.280 \mathrm{Watt}}{220 \times 0,85} \\
& =6,85 \mathrm{~A}
\end{aligned}
$$

\begin{tabular}{|c|c|c|c|c|c|}
\hline \multirow[t]{2}{*}{$\begin{array}{l}G \\
10\end{array}$} & \multirow[t]{2}{*}{$\begin{array}{l}\text { MCB } \\
\text { (A) }\end{array}$} & \multirow[t]{2}{*}{$\begin{array}{l}\mathbf{I}_{\mathbf{N}} \\
(\mathbf{A})\end{array}$} & \multicolumn{2}{|c|}{$\begin{array}{c}\text { Luas Penampang } \\
\text { Kabel }\left(\mathrm{mm}^{2}\right)\end{array}$} & \multirow[t]{2}{*}{ Ket. } \\
\hline & & & Aktual & Aturan & \\
\hline I & 10 & 6,85 & 2,5 & 2,5 & Sesuai \\
\hline II & 10 & 6,85 & 2,5 & 2,5 & Sesuai \\
\hline III & 10 & 6,85 & 2,5 & 2,5 & Sesuai \\
\hline IV & 10 & 4,3 & 2,5 & 2,5 & Sesuai \\
\hline $\mathrm{V}$ & 10 & 5,03 & 2,5 & 2,5 & Sesuai \\
\hline VI & 10 & 5,03 & 2,5 & 2,5 & Sesuai \\
\hline VII & 10 & 5,03 & 2,5 & 2,5 & Sesuai \\
\hline VIII & 10 & 6,4 & 2,5 & 2,5 & Sesuai \\
\hline IX & 10 & 6,4 & 2,5 & 2,5 & Sesuai \\
\hline $\mathrm{X}$ & 10 & 6,4 & 2,5 & 2,5 & Sesuai \\
\hline XI & 10 & 6,4 & 2,5 & 2,5 & Sesuai \\
\hline U3Ø & 43 & 18 & 10 & 10 & Sesuai \\
\hline
\end{tabular}

Tabel 1.2 Kapasitas Hantar Arus pada kabel tembaga dengan pemasangan luar.

Ket: $\mathrm{G} 1 \varnothing=$ Group dalam 1 phasa

$\mathrm{U} 3 \varnothing=$ PHB Utama 3 phasa

Hasil pengamatan untuk PHB 3 phasa diagram single line dapat diukur arus nominal dari tiap group menggunakan persamaan (3)

$$
\begin{aligned}
i_{\text {Nom }} & =\frac{S}{\sqrt{3} \times V} \\
& =\frac{5.500 \mathrm{VA}}{\sqrt{3} \times 380} \\
& =8,5 \mathrm{~A}
\end{aligned}
$$

hasil perhitungan arus nominal tiap group 3 phase dapat dilihat pada tabel 1.3 yang diperoleh arus tertinggi $8,5 \mathrm{~A}$ dengan luas penampang $2,5 \mathrm{~mm}^{2}$ dengan pengaman arus 16A masih sesuai dengan PUIL 2011;

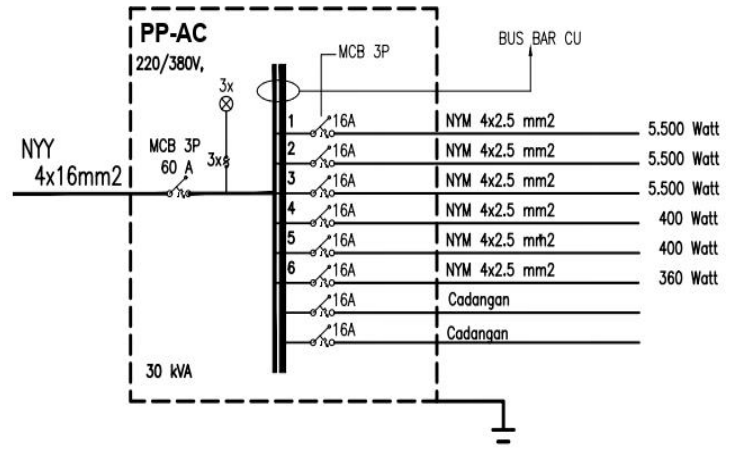

Gambar 1.5 Sistem Perlengkapan Hubung Bagi peruntukan Sistem Tata Udara.

Hasil perhitungan arus nominal dan kesesuaian instalasi listrik dengan aturan PUIL 2011 yang berlaku yang dapat dilihat pada tabel 1.3 sebagai berikut;

Tabel 1.3 Kapasitas Hantar Arus pada kabel tembaga dengan pemasangan luar.

\begin{tabular}{|c|c|c|c|c|c|}
\hline & & & \multicolumn{2}{|c|}{ Luas Penampang } & \multirow{2}{*}{ Ket. } \\
Group & MCB & $\mathbf{I}_{\mathbf{N}}$ & \multicolumn{2}{|c|}{ Kabel $\left(\mathrm{mm}^{2}\right)$} & \\
\cline { 4 - 5 } & $\mathbf{( A )}$ & $\mathbf{( A )}$ & Aktual & Aturan & \\
\hline I & 16 & 8,5 & 2,5 & 2,5 & Sesuai \\
\hline II & 16 & 8,5 & 2,5 & 2,5 & Sesuai \\
\hline III & 16 & 8,5 & 2,5 & 2,5 & Sesuai \\
\hline IV & 16 & 1 & 2,5 & 2,5 & Sesuai \\
\hline V & 16 & 1 & 2,5 & 2,5 & Sesuai \\
\hline U3Ø & 63 & 12 & 16 & 16 & Sesuai \\
\hline
\end{tabular}

Ket: $\mathrm{G} 3 \varnothing=$ Group dalam 3 phasa

$\mathrm{U} 3 \varnothing=$ PHB Utama 3 phasa

Berdasarkan penelitian maka arus maksimal yang diperoleh dari PHB sebesar 8,5 A dengan pembatas arus 16 A pada luas penampang kabel 2,5 mm2 masih sesuai dengan PUIL 2011.

\section{KESIMPULAN}

Berdasarkan penelitian maka dapat disimpulkan bahwa perancangan instalasi listrik untuk Gedung di Gedung pertemuan dengan hubungan Luas penampang Penghantar Kabel dan GPAL masih sesuai dengan persyaratan Umum Instalasi Listrik. masih sesuai dengan aturan PUIL 2011 yang berlaku sehingga dapat meningkatkan keamanan terhadap resiko kebakaran akibat penghantar (kabel) pada instalasi listrik pada Gedung bertingkat.

\section{UCAPAN TERIMA KASIH}

Ucapatan terima kasih ditujukan kepada CV Eja Malika Abadi yang telah memberi kesempatan dalam melakukan penelitian di 
Gedung pertemuan tersebut. Begitu pula pada Jurusan Teknik elektro Politeknik Negeri Ujung pandang yang memberi kesempatan dalam menyelesaikan penelitian ini.

\section{REFERENSI}

[1] N. Wakhid, "STUDI KELAYAKAN INSTALASI LISTRIK RUMAH TANGGA BERUMUR DIATAS 15 TAHUN." Universitas Islam Sultan Agung, 2019.

[2] Jakartafire.net, "Dinas Penanggulangan Kebakaran dan Penyelamatan Provinsi DKI Jakarta," 2019. .

[3] A. Subagyo, "Manajemen Resiko Kebakaran Listrik," Docplayer.Info, vol. 12, no. 1, p. 16, 2018.

[4] S. Informasi and G. Sig, "ANALISIS TINGKAT RESIKO BENCANA KEBAKARAN DI KECAMATAN MARISO KOTA MAKASSAR BERBASIS SISTEM INFORMASI GEGRAFIS (SIG) Bimo Aji

Widyantoro," pp. 94-102, 2014.

[5] N. R. Najib and K. Riyadi, "Pengembangan Deteksi Kebakaran Pada Urutan Video Dengan Menggunakan Metode Simple Linear Iterative Clustering," J. Teknol. ELEKTERIKA, vol. 17, no. 2, pp. 20 29, 2020.

[6] Kelvin, P. E. Yuliana, and S. Rahayu, "Pemetaan Lokasi Kebakaran Berdasarkan Prinsip Segitiga Api Pada Industri Textile," Semin. Nas. "Inovasi dalam Desain dan Teknol., vol. 5, no. January 2015, pp. 36-43, 2015.

[7] L. T. Eddy, "Pemeriksaan Periodik Pada Rangkaian Instalasi Listrik Bangunan Untuk Mencegah Bencana Kebakaran Melalui Penambahan Prosedur Pada SOP Penerbitan SLO Dari PLN," (Jurnal Apl. Tek. dan Pengabdi. Masy., vol. 5, no. 1, pp. 3540, 2021.

[8] R. Hidayawanti, "UPAYA TERTIB LISTRIK TERHADAP INSTALATIR KABEL DI DAERAH PADAT PENDUDUK (STUDY KASUS KEC. TAMBORA)," J. Kilat, vol. vol.7, pp. 1-90, 2018.

[9] S. N. Indonesia, "Persyaratan Umum Instalasi Listrik 2011 (PUIL 2011),"
Jakarta BSN, 2011.

[10] N. F. Alfazumi, W. Yandi, and W. Sunanda, "Uji Kelayakan Instalasi Listrik di Universitas Bangka Belitung Berdasarkan PUIL 2011 (Studi di Gedung Fakultas Teknik)," in Seminar Nasional Teknologi Informasi Komunikasi dan Industri, 2020, pp. 216-297.

[11] H. H. Sutrisno, R. Wirawan, and T. Triyono, "Uji Kemampu-Bakaran Pembungkus Kabel NYM Berstandar SNI Dengan Differencial Scanning Calorimetric," Setrum Sist. KendaliTenaga-elektronika-telekomunikasikomputer, vol. 2, no. 1, p. 22, 2013, doi: 10.36055/setrum.v2i1.236.

[12] A. M. Lutfhi, "Perhitungan Termis Dan Kemampuan Hantar Arus Kabel Bawah Tanah 20 Kv Pada Pt.Pln (Persero) Area Pontianak," pp. 0-7, 2017.

[13] P. V. \& E. S. Harten, Instalasi Listrik Arus Kuat 1. Bina Cipta, 1991.

[14] T. D. Cahyono and R. K. Pramuyanti, "Pelatihan perancangan instalasi listrik bangunan sederhana 1,2," pp. 978-979, 2020.

[15] H. S. Muhammad Ryan Nuryansyah , Didik Notosudjono, "Perencanaan Instalasi Penerangan pada Gedung Bertingkat Emerald Bintaro Tower A," pp. 1-9. 